\title{
Life Skills Training Effectiveness on Non-Metastatic Breast Cancer Mental Health: A Clinical Trial
}

\author{
Mina Shabani ${ }^{1}$; Minoosh Moghimi ${ }^{2}$; Reza Eghdam Zamiri ${ }^{3}$; Fatemeh Nazari $^{2}$; Nouraddin $^{2}$ \\ Mousavinasab ${ }^{4}$; Zahra Shajari ${ }^{5,}$ \\ ${ }_{1}^{1}$ Department of Psychiatry, Zanjan University of Medical Sciences, Zanjan, IR Iran \\ ${ }_{3}^{2}$ Departments of Hematology and Oncology, Zanjan University of Medical Sciences, Zanjan, IR Iran \\ ${ }^{3}$ Department of Radiation Oncology, Zanjan University of Medical Sciences, Zanjan, IR Iran \\ ${ }^{4}$ Department of Statistics, Faculty of Medicine, Zanjan University of Medical Sciences, Zanjan, IR Iran \\ 5 Zanjan Metabolic Disease Research Center, Zanjan University of Medical Sciences, Zanjan, IR Iran \\ ${ }^{*}$ Corresponding Author: Zahra Shajari, Zanjan Metabolic Disease Research Center, Zanjan University of Medical Sciences, Zanjan, IR Iran. Tel: +98-2417270814, Fax: +98-2417270815, \\ E-mail:adz.shajari@gmail.com
}

Received: October 24, 2012; Accepted: May 11, 2013

Background: Patients with breast cancer are predisposed to some psychiatric symptoms and mental disorders due to their life styles or disease conditions. These problems cause patients to deal with daily stress, feeling guilty, anxiety, dysphoric mood, and impaired social relations. Such problems would lead to serious mental disorders.

Objectives: Therefore, life skills training may help patients to cope better with their condition, and improve their mental health.

Materials and Method: In an experimental study, 50 patients with breast cancer were selected randomly and assigned to 2 experimental and control groups. The experimental group attended life skills training classes for 10 weeks continuously (each class lasting 2 hours). Participants in both the experimental and control groups completed a GHQ-28 questionnaire form before the commencement of classes, and again after 2 weeks to 2 months of the course completion. T-test was used as the statistical method.

Results: In life skills training group, depressive and anxiety symptoms, somatization disorders, sleep disorders and disorders of social functioning were significantly decreased $(\mathrm{p}<0.0001)$. These changes were not observed in the control group.

Conclusions: The results showed that life skills training is an effective method in reducing symptoms of depression, anxiety, sleep and somatic disorders. Also, it would be useful in reducing problems of social dysfunction.

Keywords: Breast Neoplasms; Life; Skill; Education; Quality of Life

\section{Background}

Breast cancer is the most common type of cancer among women worldwide (1-3), which accounts for approximately one-fifth of all deaths in women aged $40-50$ years (4). In Iran, its incidence was estimated to be 20 per 105 women, and one of every 10 women would develop breast cancer during her life (5-7). Treatment options include surgery, radiotherapy, and chemotherapy which lead to increased disease- free survival, better tumor response, and overall survival improving. On the other hand, cancer and therapies complications have confronted patients with terrifying psychological experiences and morbidities like anxiety, depression, and poor quality of life.

Previous reviews of the literature have indicated that psychological therapies and life skills training may help patients with cancer by increasing their knowledge about their disease and treatment, by improving their emotional adjustment, satisfaction, and their physical condition, and reducing treatment and disease-related symptoms (8-12). Besides improving conditional therapies for patients with breast cancer, tendency to use new psychological interventions is growing. One of these psychological packages is life skills training program defined by WHO as ability for adaptive and positive behaviors which enables individuals to deal effectively with the demands and challenges of everyday life, and consists of 10 abilities (13).

\section{Objectives}

We designed a clinical trial to examine the effects of life

Implication for health policy/practice/research/medical education:

Mental health improving after life skills training in non-metastatic breast cancer was up to us to arrange a study in our area. While reviewing these data, psychological consultation therapies recommended for patients with cancer because they expect these therapies to cure their cancer or to improve their recovery and both patients and oncologists would be moderately satisfied with the results of psychological therapies.

Copyright (c) 2013, Iranian Red Crescent Medical Journal; Published by Kowsar Corp. This is an open-access article distributed under the terms of the Creative Commons Attribution License, which permits unrestricted use, distribution, and reproduction in any medium, provided the original work is properly cited. 
skills training on psychological distress and coping with primary breast carcinoma among Iranian women.

\section{Materials and Methods}

\subsection{Subjects}

Fifty subjects with diagnosed breast carcinoma in department and clinic of oncology in Vali-e-Asr hospital were selected. The study protocol was reviewed and approved by the Department of Internal Medicine and the Ethics Committee of Zanjan University of Medical Sciences, Iran. Eligibility criteria for the current study population were: 1) age younger than 65 years; 2) diagnosed breast carcinoma in stages I, II or III who completed standard therapy including mastectomy, chemotherapy, and radiotherapy and being under hormone therapy during the clinical trial. Exclusion criteria were mental disorders, dementia, psychosis or acute psychological disorder like major depression, or if they had cancer at another site. None of the subjects had received psychological consult before the study participation. Eligible subjects were informed for this psychosocial group intervention and life skill training study. They were informed that all cancer patients experience psychological distress, and this life skills training is useful for improving the quality of life of patients with breast carcinoma according to the same researched performed in other countries. All patients provided written informed consent before the assessment.

\subsection{Intervention Protocol}

Patients who wished to participate in the intervention and met the eligibility criteria were randomly categorized to either the experimental group or the control group (each containing 25 subjects) by using their birth certificate number. Demographic information of patients included age, education, number of children, occupation, income, and the duration of breast cancer were recorded in a questionnaire. Because previous studies have shown that individual intervention requires too much time and cost in comparison to group intervention (14-18), and group intervention to be as effective in solidarity and interaction between group and emotional draining $(15,19,20)$, we chose a group model in this study. We aligned 10 sessions, for 2 hours and lasting, totally, in 10 weeks. In these workshops 10 life skills and techniques (decision making, problem solving, creatively thinking, critically thinking, communication skill, interpersonal relationship, self-confidence, feeling empathy, emotion handling, and tension handling recommended by WHO) (18) and skill application in patients' lives were taught by trained and qualified trainers during these workshops and observed by psychologists. At the end of each ses- sion, subjects were assessed about skill of that session, and trainers resolved their questions.

\subsection{Measurement}

The General Health Questionnaire-28 (GHQ) was designed by Goldberg DP (21), and its reliability and validity were assessed $(15,22)$, standardized for screening in Persian language, in Iran. It has four subscales: 1) somatization symptoms, 2) anxiety and sleeping disorders, 3) social functioning, and 4) depression (D). Each subscale contains 7 'here and now' questions. Scoring system of GHQ questions was based on psychological discomfort (lowest score $=1$ ) up to psychological health (highest score $=4$ ). The total score of each question varies from 7 to 28 , and the total range for score of General Health Questionnaire is estimated from 28 to 112. In this questionnaire, psychiatric symptoms and abnormal behaviors of patients were elicited. Subjects completed GHQ-28 just before the training workshop, at the end of 2 weeks education period, and 2 months after the completion of training courses. Lower scores indicated more impaired psychological condition.

\subsection{Statistical Analysis}

Statistical analysis was performed using the Statistical Package for Social Science (SPSS version 16). Mean values ( \pm SEM), median, ranges are shown. Descriptive statistical methods were used where appropriate. Demographic and clinical characteristics and baseline psychological scores were tested by the Student $\mathrm{T}$ test. Preliminary analyses included descriptive and bivariate analyses (i.e. analyses of variance and to examine comparability between the groups on socio demographic, medical, and baseline QOL characteristics.

\section{Results}

This study was conducted among 50 patients with breast cancer in different stages of carcinoma I, II, III who had completed their standard therapy before psychological intervention; they were divided into 2 experimental and control groups randomly. The mean age was $46.7 \pm$ 9.3 years in the intervened patients, compared to $45.7 \pm$ 8.9 in the control subjects, with no significant difference $(P=0.714)$. Demographic and social characteristics of the 2 groups were summarized in Table 1 . There was no difference between both groups regarding their occupation, education level, number of children, and monthly income. The mean time of illness awareness was $2.64 \pm$ 1.22 years for the experimental group, and $2.68 \pm 1.94$ for the control group $(\mathrm{P}=0.897)$.

GHQ-28 scores of 4 subtitles include somatization symptoms, anxiety and sleep disorders, social function disorder, and depression disorder (Table 2). 
Shabani M et al.

\begin{tabular}{|c|c|c|c|}
\hline Character & Experimental Group & Control Group & PValue \\
\hline Occupation & & & 0.384 \\
\hline House wife & 23 & 21 & \\
\hline Employed & 2 & 4 & \\
\hline Education & & & 0.972 \\
\hline Illiteracy & 2 & 2 & \\
\hline Elementary school & 15 & 14 & \\
\hline High school & 6 & 6 & \\
\hline University & 2 & 3 & \\
\hline Number of children & & & 0.57 \\
\hline 2 & 4 & 4 & \\
\hline 3 & 7 & 9 & \\
\hline 4 & 8 & 7 & \\
\hline 5 & 4 & 4 & \\
\hline 6 & 2 & 1 & \\
\hline Month income & & & 0.765 \\
\hline Under $200 \$$ & 8 & 9 & \\
\hline Over $200 \$$ & 17 & 16 & \\
\hline $\begin{array}{l}\text { Illness awareness, mean } \pm \\
S D, y, n=25\end{array}$ & $2.64 \pm 1.22$ & $2.68 \pm 0.94$ & 0.897 \\
\hline
\end{tabular}

Table 2. Scores for 4 GHQ-28 Subtitles of Experimental and Control Groups Before and After Life Skills Training

\begin{tabular}{|c|c|c|c|c|c|c|}
\hline \multirow[t]{2}{*}{ Subtitle } & \multicolumn{3}{|c|}{ Experimental Group, $\mathbf{n}=\mathbf{2 5}$} & \multicolumn{3}{|c|}{ Control Group, $\mathbf{n}=25$} \\
\hline & Before & 2 Weeks After & 2 Months After & Before & 2 Weeks After & 2 Months After \\
\hline $\begin{array}{l}\text { Psychosomatic } \\
\text { symptoms }\end{array}$ & 19 & 21.68 & 20.6 & 19.52 & 19 & 19.64 \\
\hline $\begin{array}{l}\text { Anxiety and } \\
\text { sleep disorders }\end{array}$ & 13.28 & 19.52 & 19.36 & 19.28 & 19.65 & 22.28 \\
\hline $\begin{array}{l}\text { Social function } \\
\text { disorder }\end{array}$ & 19.64 & 23.12 & 22.28 & 19.04 & 19.24 & 19.64 \\
\hline $\begin{array}{l}\text { Depression } \\
\text { disorder }\end{array}$ & 13.76 & 16.28 & 16.20 & 12.64 & 12.76 & 12.2 \\
\hline Total score & 65.68 & 80.6 & 78.4 & 70.48 & 70.46 & 73.76 \\
\hline
\end{tabular}

Data analysis indicated that somatization symptoms score increased 2 weeks after the intervention significantly $(\mathrm{P}<0.001)$, and this increment persisted after 2 months too $(\mathrm{P}<0.00001)$. These differences were not observed in the control group. Anxiety and sleep disorders assessment of experimental group revealed a considerable increase in the score before skill training (13.2 \pm 2 ) compared to 2 weeks after the training $(19.5 \pm 2)$ ( $P$ $<0.00001)$. Changes in anxiety and sleep disorders remained after 2 months ( $\mathrm{P}<0.001)$. After 2 weeks of life skills training workshop, social function disorder scale improved and reached $23.1 \pm 1(\mathrm{P}<0.0001)$, and after 2 months, this increase was statistically significant compared to the score before the intervention $(\mathrm{P}<0.001)$.

Mean score of depression disorder phase before the experiment was $13.7 \pm 4,2$ weeks after the experiment increased to $16.2 \pm 4$, and 2 months later, remained 16.2 \pm 2 . This score was $12.6 \pm 1$ for the control group at baseline, which did not change after 2 weeks and 2 months of reassessment. The total score of questionnaire in the experimental group was estimated 65.68 before the intervention, but increased up to 80.6 after 2 weeks, which was statistically significant and was persistent even after 2 months. These changes were not observed in the control group (Table 2). Also, means of changes were compared in three categories between the two groups. First; before and after 2 weeks of intervention, the second; before and 2 months after, and the third, comparison of changes between the results of after 2 weeks and after 2 months. Results demonstrated that differences between the means 
Shabani M et al.

of changes were considerable in the experimental group (Table 3). These Mean scores of 4 subtitles before and 2 weeks and 2 months after life skills training workshop were illustrated in Figures 1, 2, 3, 4, and 5.

\begin{tabular}{|c|c|c|c|c|c|c|}
\hline \multirow{2}{*}{$\begin{array}{l}\text { Time and } \\
\text { Groups, } n=25\end{array}$} & \multicolumn{6}{|c|}{ Mean of Changes } \\
\hline & $\begin{array}{l}\text { Before and } \\
\text { After } 2 \text { Weeks }\end{array}$ & Pvalue & $\begin{array}{l}\text { Before and } \\
\text { After } 2 \text { Weeks }\end{array}$ & Pvalue & $\begin{array}{l}2 \text { Weeks and } 2 \\
\text { Months After }\end{array}$ & Pvalue \\
\hline $\begin{array}{l}\text { Psychosomatic } \\
\text { Symptom }\end{array}$ & - & $<0.00001$ & - & $<0.00001$ & - & 0.002 \\
\hline $\begin{array}{l}\text { Experi- } \\
\text { mental } \\
\text { Group }\end{array}$ & 2.68 & - & 1.6 & - & 1.08 & - \\
\hline $\begin{array}{l}\text { Control } \\
\text { group }\end{array}$ & -0.62 & - & 0.12 & - & 0.64 & - \\
\hline $\begin{array}{l}\text { Anxiety and } \\
\text { sleep disorder }\end{array}$ & - & $<0.00001$ & - & 0.001 & - & $<0.00001$ \\
\hline $\begin{array}{l}\text { Experi- } \\
\text { mental } \\
\text { Group }\end{array}$ & 6.24 & - & 6.08 & - & -0.16 & - \\
\hline $\begin{array}{l}\text { Control } \\
\text { group }\end{array}$ & 0.36 & - & 3 & - & 2.64 & - \\
\hline $\begin{array}{l}\text { Social function } \\
\text { disorder }\end{array}$ & - & $<0.00001$ & - & 0.001 & - & 0.02 \\
\hline $\begin{array}{l}\text { Experi- } \\
\text { mental } \\
\text { Group }\end{array}$ & 3.48 & - & 2.64 & - & -0.84 & - \\
\hline $\begin{array}{l}\text { Control } \\
\text { group }\end{array}$ & 0.2 & - & 0.6 & - & 0.4 & - \\
\hline $\begin{array}{l}\text { Depression } \\
\text { disorder }\end{array}$ & - & $<0.0001$ & - & 0.0001 & - & 0.28 \\
\hline $\begin{array}{l}\text { Experi- } \\
\text { mental } \\
\text { Group }\end{array}$ & 2.52 & - & 2.44 & - & -0.08 & - \\
\hline $\begin{array}{l}\text { Control } \\
\text { group }\end{array}$ & 0.12 & - & -0.044 & - & -0.56 & - \\
\hline Total score & - & $<0.0001$ & - & $<0.0001$ & - & $<0.0001$ \\
\hline $\begin{array}{l}\text { Experi- } \\
\text { mental } \\
\text { Group }\end{array}$ & 14.94 & - & 12.76 & - & -2.16 & - \\
\hline $\begin{array}{l}\text { Control } \\
\text { group }\end{array}$ & 0.16 & - & 3.28 & - & 3.12 & - \\
\hline
\end{tabular}

\section{Discussion}

Breast cancer is the most common type of cancer among women worldwide. For women, breast cancer is a terrifying disease due to a high mortality rate and body imaging distortion (1-3). Most patients with breast cancer have psychological reactions such as denial, anger, or fear toward their disease and treatment process. Many patients have psychiatric morbidities, especially anxiety and depressive disorders (23-25). Among psychiatric morbidities, anxiety and depressive disorders are the two disorders commonly found in patients with breast cancer. The range of anxiety disorder prevalence in breast can- cer varied from 1 to $49 \%$ (26), while depressive disorder ranged from 1.5 to $46 \%(26,27)$.

In the recent years, there has been increasing interest in various aspects of mental health. Also, it is considered that psychosocial intervention could reduce the morbidity of patients breast carcinoma, improve the quality of life of patients with cancer, and its effects have been evaluated over the past 2 decades $(21,28-34)$. Health promotion is defined as 'any deliberate intervention which seeks to promote health and prevents disease disability' (35-38). WHO then defined a developed training program, with the aim of mental health promotion, named life skills. It 
means ability for adaptive and positive behavior which enables individuals to deal effectively with the demands and challenges of everyday life (13). The main purpose of life skills training is to promote healthy lifestyles through skills training.

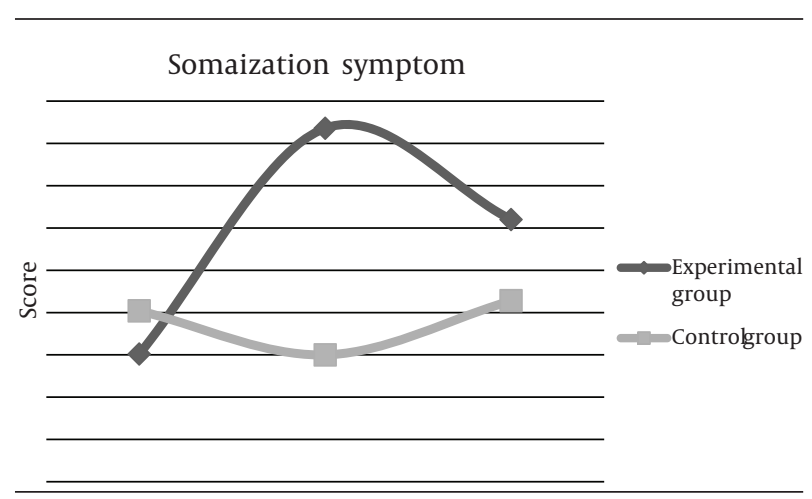

Figure 1. Comparison of Mean Score Changes in Psychological Symptoms (GHQ-28) Before and After Life Skills Training in Experimental and Control Groups

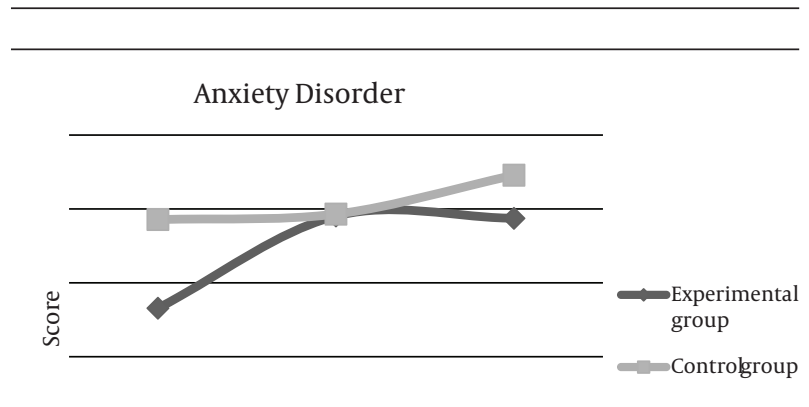

Figure 2. Comparison of Mean Score Changes in Anxiety Symptoms (GHQ-28) Before and After Life Skills Training in Experimental and Control Groups

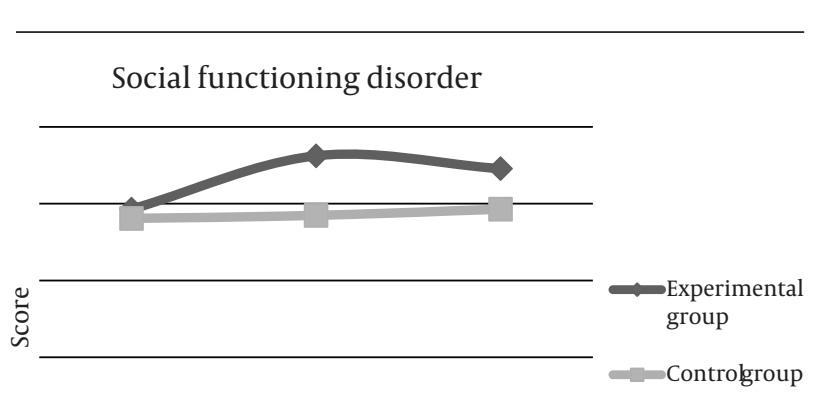

Figure 3. Comparison of Mean Score Changes in Social Functioning Disorder (GHQ-28) Before and After Life Skills Training in Experimental and Control Groups

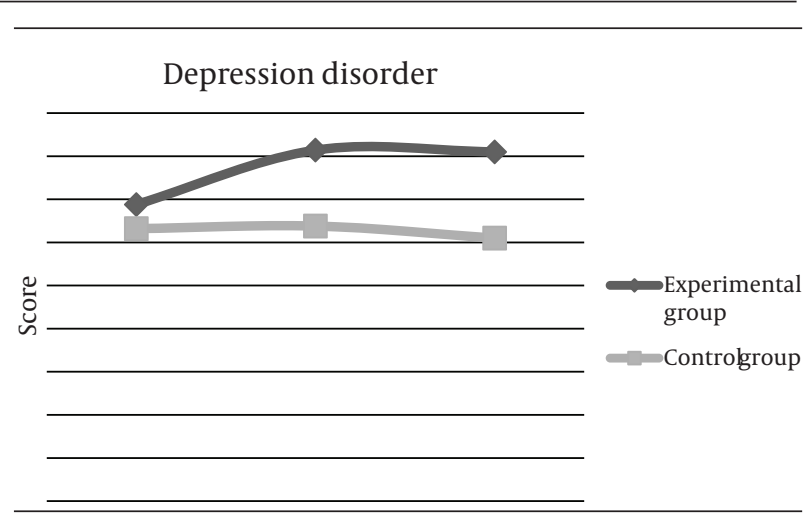

Figure 4. Comparison of Mean Score Changes in Depression Disorder (GHQ-28) Before and After Life Skills Training in Experimental and Control Groups

Total score of GHQ28-

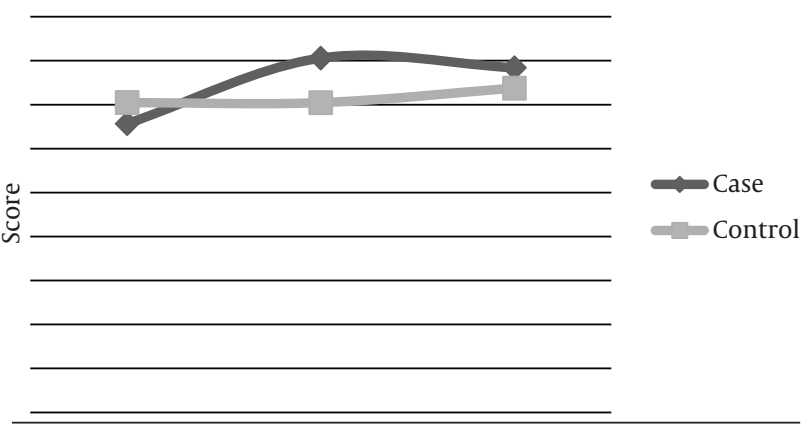

Figure 5. Comparison of Mean Score Changes in Total Score of GHQ-28 Questionnaire Before and After Life Skills Training in Experimental and Control Groups

These following life skills (recommended by WHO) (18) are:

1. The ability to make decisions helps people assess their options and carefully consider the different consequences that can result from their choices.

2. The ability to solve problems helps people find constructive solutions to their problems. This skill can significantly reduce anxiety.

3. The capacity to think creatively helps people make decision and solve problem, and look beyond their personal experience.

4. The capacity to think critically helps people analyze information along with their own experiences.

5. The ability to communicate effectively helps people express their feelings, needs, and ideas to others.

6 . The ability to establish and maintain interpersonal relations helps people interact positively with people whom they encounter daily, especially family members.

7. Knowledge of self is the capacity of people to know 
who they are, what they want and do not want, and what does and does not please them which helps people recognize stressful situations.

8. The capacity to feel empathy is the ability to imagine what life is like for another person in a very different situation. It helps people to understand and accept diversity, and it also improves interpersonal relations between diverse individuals.

9. The ability to handle emotions enables subjects to recognize their emotions and how they influence their behaviors.

10. The ability to handle tension and stress $(34,39)$.

Efficacy of life skill training and psychological intervention depends on many variables such as (40) patients' clinical and demographic characteristics like cancer stage and course of the disease, medical treatment, age, and gender, and educational level, income, occupation (41), and duration of psychosocial interventions; for example results of a meta-analysis indicated that the most important moderating variable was duration of psychosocial intervention and durations over 12 weeks would be more effective significantly rather than shorter durations (42). Moreover, the methodological quality of intervention studies; choosing a control groups, randomization status of treatment conditions, or documentation of experimental and statistical designs and procedures can lead to a higher mental health level.

Studies on the effectiveness of life skills training either on the normal population quality of life or subjects with other bodily problems confirmed efficacy of these educations. For example working women predisposed to many psychiatric symptoms or disorders were attended 1-2 sessions of life skills training weekly for 10 weeks. The results of this study showed that life skills training can be an effective method in reducing anxiety, sleep and somatic symptoms of subjects (43). Or results of quality of life evaluation in 40 patients with coronary heart aged 35-65 years, having bypass for the first time after life skills training program showed that group life skills training is effective to decrease anxiety and depression in patients with coronary diseases after coronary bypass surgery (44). In the recent study, we evaluated efficacy and psychological power of life skills training program on improvement of non-metastatic breast cancer quality of life. As described in materials and methods, GHQ-28 questionnaire was designed in a way as lower scores indicate poor mental and physical condition, and a higher score expresses a better, healthy mental status. In this study, in spite of training the ways of increasing self-esteem and controlling feelings in training sessions, but we did not measure their effects on quality of life. As indicated in this study, there were not significant differences in 4 GHQ-28 items including 1) somatization symptoms, 2) anxiety and sleeping disorders, 3) social functioning disorder, and 4) depression between the experimental and control groups before life skills training intervention. After 2 weeks of psychological intervention, we found a remarkable reduction in somatization symptoms, anxiety and sleeping disorders, social functioning disorder and depression symptoms in the experimental group compared to the control and before the intervened condition. Also, life skills training effectiveness on quality of life and anxiety and depression reduction remained after 2 months of reassessment.

The result of a meta-analysis summarized the results of 37 published, controlled studies that investigated the effectiveness of psychosocial interventions on quality of life (QoL) in adult patients with cancer, and findings supported the usefulness of psychosocial interventions for improving quality of life in adult patients with cancer (45). Three hundred female patients with breast cancer, aged above 18 years old from the Surgical Outpatient Department, King Chulalongkorn Memorial Hospital were evaluated in a study from December 2006 to May 2007, and showed that anxiety and depressive disorders are the two common psychiatric disorders in patients with breast cancer. Improving patients' social support and raising patient's coping skills reduced the patients' psychological stress and psychiatric morbidities (39).

Japanese scientists conducted a 6-week, psychosocial group intervention on patients with breast cancer with the followings inclusion criteria; age younger than 65 years, lymph node metastasis positive and/or histologic or nuclear grade $2-3$, and undergone surgery within the past 4-18 months from the beginning of study. The intervention consisted of health education, coping skills training, stress management, and psychological supports. Patients were evaluated for psychological distress by the Profile of Mood States (POMS), Mental Adjustment to Cancer (MAC) scale, and Hospital Anxiety and Depression (HADS) scale. They inferred that short term psychosocial intervention produces significant long term enhancing of quality of life in Japanese patients with primary breast cancer (46). Thirty-six patients with nonmetastatic breast cancer were assessed in G. Marchioro et al. investigation. Patients received either psychological intervention (weekly cognitive individual psychotherapy and bimonthly family counseling) or standard follow-up. Personality (16-PF and IIQ), quality of life (FLIC), and depression (BDI) scores were the endpoints for this study, and evaluated in the patients at diagnosis, and up to 9 months after the diagnosis. This study indicated that cognitive psychotherapy and family counseling improved both depression and quality of life indices compared to the control group (30).

Therefore, by citing to the previous researches findings and this study; psychological consultation therapies are recommended for patients with cancer because they expect these therapies to cure their cancer or to improve their recovery and both patients and oncologists would be moderately to very satisfied with the results of psychological therapies. In conclusion, many investigations concluded that psychological therapies might help patients with cancer in various ways, ranging from reducing the 
side effects of cancer treatments to improving patients' immune function and longevity.

\section{Acknowledgements}

This study was approved by the ethical committee of Zanjan University of Medical Sciences and department of hematology and oncology and radiation oncology.

\section{Authors' Contributions}

All the authors collaborated during the investigation process, on all phases of the project including primary data collection, analysis and documentation of the collection and compilation of papers have supervised and all coauthors read and accepted the contents of the manuscript, and there is no financial interest to report and no disclosure.

\section{Financial Disclosure}

There is no financial relationship with the organization that sponsored the research and authorship.

\section{Funding/Support}

This research was supported financially as a research project by Zanjan University of Medical Sciences, Zanjan, IR Iran.

\section{References}

1. Hortobagyi GN, de la Garza Salazar J, Pritchard K, Amadori D, Haidinger R, Hudis CA, et al. The global breast cancer burden: variations in epidemiology and survival. Clin Breast Cancer. 2005;6(5):391-401.

2. Key TJ, Verkasalo PK, Banks E. Epidemiology of breast cancer. Lancet Oncol. 2001;2(3):133-40.

3. Yankaskas BC. Epidemiology of breast cancer in young women. Breast Dis. 2005;23:3-8.

4. Yen JY, Ko CH, Yen CF, Yang MJ, Wu CY, Juan CH, et al. Quality of life, depression, and stress in breast cancer women outpatients receiving active therapy in Taiwan. Psychiatry Clin Neurosci. 2006;60(2):147-53.

5. Andrykowski MA, Curran SL, Studts JL, Cunningham L, Carpenter JS, McGrath PC, et al. Psychosocial adjustment and quality of life in women with breast cancer and benign breast problems: a controlled comparison. J Clin Epidemiol.1996;49(8):827-34.

6. Psychological response to mastectomy. A prospective comparison study. Psychological aspects of Breast Cancer Study Group. Cancer.1987;59(1):189-96.

7. Northouse LL. Mastectomy patients and the fear of cancer recurrence. Cancer Nurs. 1981;4(3):213-20.

8. Fawzy FI, Fawzy NW, Arndt LA, Pasnau RO. Critical review of psychosocial interventions in cancer care. Arch Gen Psychiatry. 1995;52(2):100-13.

9. Devine EC, Westlake SK. The effects of psychoeducational care provided to adults with cancer: meta-analysis of 116 studies. Oncol Nurs Forum. 1995;22(9):1369-81.

10. Burke Susan, Kissane DavidWilliam. Psychosocial support for breast cancer patients: a review of interventions by specialist providers: a summary of the literature 1976-1996.Sydney, Australia: NHMRC National Breast Cancer Centre; 1998.

11. Rimer B, Keintz MK, Glassman B. Cancer patient education: reality and potential. Prev Med.1985;14(6):801-18.

12. Meyer TJ, Mark MM. Effects of psychosocial interventions with adult cancer patients: a meta-analysis of randomized experi- ments. Health Psychol.1995;14(2):101-8.

13. Life skills education for children and adolescents in schools: Introduction and guidelines to facilitate the development and implementation of life skills programs.Geneva, Switzerland: World Health Organization; 1997.

14. Kreutter KJ, Gewirtz H, Davenny JE, Love C. Drug and alcohol prevention project for sixth graders: first-year findings. Adolescence. 1991;26(102):287-93.

15. Goldberg DP, Gater R, Sartorius N, Ustun TB, Piccinelli M, Gureje $\mathrm{O}$, et al. The validity of two versions of the GHQ in the WHO study of mental illness in general health care. Psychol Med. 1997;27(1):191-7.

16. Palahang H, Nasr M, Barahani MT, Shahmohammadi D. Epidemiology of psychiatric disorders in Kashan. Andisheh van Raftar. 2006;2(4):19-27.

17. Yaghubi N, Nasr M, Shahmohammadi D. Epidemiology of mood disorders in urban and rural areas of Sowmaesara-Gillan. Andisheh van Raftar. 1995;1(4):55-65.

18. Skills for Life. WHO/MNH/NLSL.1993;93:1.

19. Schimmel-Spreeuw A, Linssen AC, Heeren TJ. Coping with depression and anxiety: preliminary results of a standardized course for elderly depressed women. Int Psychogeriatr. 2000;12(1):77-86.

20. Bellack AS, Turner SM, Hersen M, Luber RF. An examination of the efficacy of social skills training for chronic schizophrenic patients. Hosp Community Psychiatry. 1984;35(10):1023-8.

21. Fawzy FI, Fawzy NW. A structured psychoeducational intervention for cancer patients. Gen Hosp Psychiatry. 1994;16(3):149-92.

22. Allison DB, Allison DB, Baskin ML. Handbook of Assessment Meth ods for Eating Behaviors and Weight-Related Problems: Measures, Theory, and Research.Thousand Oaks, CA, USA: SAGE Publications; 2009.

23. Schover LR. The impact of breast cancer on sexuality, body image, and intimate relationships. CA Cancer JClin.1991;41(2):112-20.

24. Oktay JS. Psychosocial aspects of breast cancer. Lippincotts Prim Care Pract.1998;2(2):149-59.

25. Rabinowitz B. Psychosocial issues in breast cancer. Obstet Gynecol Clin North Am. 2002;29(1):233-47.

26. Morasso G, Costantini M, Viterbori P, Bonci F, Del Mastro L, Musso $\mathrm{M}$, et al. Predicting mood disorders in breast cancer patients. Eur J Cancer. 2001;37(2):216-23.

27. Massie MJ. Prevalence of depression in patients with cancer. $J$ Natl Cancer Inst Monogr. 2004(32):57-71.

28. Spiegel D, Bloom JR, Yalom I. Group support for patients with metastatic cancer. A randomized outcome study. Arch Gen Psychiatry. 1981;38(5):527-33.

29. Bridge LR, Benson P, Pietroni PC, Priest RG. Relaxation and imagery in the treatment of breast cancer. BMJ.1988;297(6657):1169-72.

30. Marchioro G, Azzarello G, Checchin F, Perale M, Segati R, Sampognaro $\mathrm{E}$, et al. The impact of a psychological intervention on quality of life in non-metastatic breast cancer. Eur J Cancer. 1996;32A(9):1612-5.

31. McArdle JM, George WD, McArdle CS, Smith DC, Moodie AR, Hughson AV, et al. Psychological support for patients undergoing breast cancer surgery: a randomised study. BMJ. 1996;312(7034):813-6.

32. Leszcz M, Goodwin PJ. The rationale and foundations of group psychotherapy for women with metastatic breast cancer. Int Group Psychother.1998;48(2):245-73.

33. Braden CJ, Mishel MH, Longman AJ. Self-Help Intervention Project. Women receiving breast cancer treatment. Cancer Pract. 1998;6(2):87-98.

34. Coward DD. Facilitation of self-transcendence in a breast cancer support group. Oncol Nurs Forum. 1998;25(1):75-84.

35. Tsukuma H, Kitagawa T, Hanai A, Fujimoto I, Kuroishi T, Tominaga $\mathrm{S}$. [Incidence of cancer prediction in Japan up to the year 2015].Jpn J Cancer Clin.1992;38(1):1-10.

36. Fallowfield LJ, Hall A, Maguire GP, Baum M. Psychological outcomes of different treatment policies in women with early breast cancer outside a clinical trial. BMJ.1990;301(6752):575-80.

37. Goldberg JA, Scott RN, Davidson PM, Murray GD, Stallard S, George WD, et al. Psychological morbidity in the first year after breast surgery. EurJ Surg Oncol. 1992;18(4):327-31. 
38. Carlsson M, Hamrin E. Psychological and psychosocial aspects of breast cancer and breast cancer treatment. A literature review. Cancer Nurs. 1994;17(5):418-28.

39. Lueboonthavatchai P. Prevalence and psychosocial factors of anxiety and depression in breast cancer patients. J Med Assoc Thai. 2007;90(10):2164-74.

40. van't Spijker A, Trijsburg RW, Duivenvoorden HJ. Psychological sequelae of cancer diagnosis: a meta-analytical review of 58 studies after 1980. Psychosom Med.1997;59(3):280-93.

41. Andersen BL. Psychological interventions for cancer patients to enhance the quality of life. J Consult Clin Psychol. 1992;60(4):55268.

42. Bottomley A. Where are we now? Evaluating two decades of group interventions with adult cancer patients. J Psychiatr Ment Health Nurs. 1997;4(4):251-65.
43. Moinalghorabaei Mahdieh, Sanati Mohammad. Evaluation of the effectiveness of life skills training for Iranian working women. Iran J Psychiatry Behav Scie. 2008;2(2):23-29.

44. Nemati Sogolitappeh Fatemeh, Mahmood Aliloo Majid, Babapur Kheyroddin Jalil, Toufan Tabrizi Mehrnoosh. Effectiveness of group life skills training on decreasing anxiety and depression among heart patients, after bypass surgery. Iran J Psychiatry Clin Psychology. 2009;15(1):50-56.

45. Rehse B, Pukrop R. Effects of psychosocial interventions on quality of life in adult cancer patients: meta analysis of 37 published controlled outcome studies. Patient Educ Couns. 2003;50(2):17986.

46. Fukui S, Kugaya A, Okamura H, Kamiya M, Koike M, Nakanishi $\mathrm{T}$, et al. A psychosocial group intervention for Japanese women with primary breast carcinoma. Cancer. 2000;89(5):1026-36. 